\title{
Physical fitness and future cardiovascular risk in argentine children and adolescents: an introduction to the ALPHA test battery
}

\author{
Jeremías David Secchi , Magister, Gastón César Garcíab , M.D., \\ Vanesa España-Romeroc, M.D. and José Castro-Piñero ${ }^{d}$, M.D.
}

\begin{abstract}
Introduction. A high level of physical fitness is associated with cardiovascular health in children and adolescents. At present, there is no systematic implementation of a test battery to assess physical fitness at schools in Argentina. The main objective of this study was to implement the ALPHA test battery to determine the physical fitness of a sample made up of Argentine children and adolescents and to establish the proportion of subjects whose aerobic capacity is indicative of future cardiovascular risk.

Population and methods. A sample of 1867 participants (967 girls) aged 6 to 19.5 years old assessed using the ALPHA test battery. Four components of physical fitness were measured: 1 ) morphological component: height, body weight, and waist circumference; 2) musculoskeletal component: standing long jump test; 3 ) motor component: speed/agility test $(4 \times 10 \mathrm{~m}$ shuttle run); 4) cardiorespiratory component: coursenavette $20 \mathrm{~m}$, shuttle run test and estimation of maximal oxygen consumption. The $5^{\text {th }}, 25^{\text {th }}$, $50^{\text {th }}, 75^{\text {th }}$, and $95^{\text {th }}$ percentiles were estimated for the main tests.

Results. The mean body mass index was $20.8 \mathrm{~kg} /$ $\mathrm{m} 2$, and $7.8 \%$ of participants were classified as obese. In addition, male participants had a better performance in all physical fitness tests when compared to girls $(p<0.001)$. An aerobic capacity indicative of cardiovascular risk was observed in $31.6 \%$ of all participants.

Conclusions. Argentine male children and adolescents included in the sample showed higher levels of physical fitness. Such differences increase with age. Approximately one every three participants had an aerobic capacity indicative of future cardiovascular risk.

Key words: physical fitness, children, adolescents, course-navette $20 \mathrm{~m}$ test, cardiovascular risk.
\end{abstract}

http:/ /dx.doi.org/10.5546/aap.2014.eng.132

\section{INTRODUCTION}

The assessment of physical fitness $(\mathrm{PF})$ in the school setting is a field of research that first originated in the 1950's. ${ }^{1}$

However, the original concept regarding PF assessment at school has drastically changed over the past 20 years. ${ }^{1,2}$ The focus went from performance-centered PF to healthrelated $\mathrm{PF}$, thus modifying how the assessment of PF is understood and interpreted. ${ }^{3-5}$

An adequate PF assessment program would be effective to 1 ) encourage students, 2) know their PF level, 3) check their progress, 4) identify risk factors, ${ }^{6,7} 5$ ) design physical activity programs, and 6) promote health and physical education. ${ }^{8}$ In addition, recent scientific evidence has confirmed that a high level of PF is strongly related to the cardiovascular, metabolic, musculoskeletal and mental health of children and adolescents. ${ }^{9,10}$

At school, PF is assessed using a physical fitness test battery (PF-TB). The advantages of PF-TB include that it allows to assess several subjects at the same time, takes little time, is safe, easily administered, and has a low cost, making it adequate for epidemiological studies. ${ }^{11}$ No definition was found in the scientific literature on PF-TB. In our concept, PF-TB can be defined as a set of field tests for assessing different components of PF and which can be, individually or as a whole, related to sports performance (performance-related PF-TB) or to an individual's specific present and future health aspects (health-related PF-TB).

The most well-known PF-TB include EUROFIT, FITNESSGRAM, and the recently published ALPHA test battery. ${ }^{12,13}$ The latest has been developed based on solid scientific evidence to provide a set of valid, reliable, feasible and safe tests which have been scientifically proven to be related to the present and future health of children and adolescents. ${ }^{13,14}$

Unfortunately, no valid and reliable PF-TB has been established as an indicator of health in children and 
adolescents in the Argentine public or private school system. Moreover, as per our knowledge, there is no published scientific study describing PF levels in relation to health in the Argentine pediatric population.

The main objective of this study was to implement the ALPHA test battery to determine the PF of a sample made up of Argentine children and adolescents and to establish the proportion of subjects whose aerobic capacity is indicative of future cardiovascular risk.

\section{POPULATION AND METHODS}

\section{Study sample and design}

The study was conducted between April $9^{\text {th }}$ and October $30^{\text {th }}, 2012$ on a convenience sample made up of Argentine children and adolescents aged 6 to 19.5 years old. The study design was observational, descriptive and cross-sectional. The assessment was conducted in primary and secondary schools located in ten cities from five Argentine provinces (Entre Ríos, Mendoza, Buenos Aires, Misiones, and Santa Cruz). A total of 16 schools took part: ten public and six private schools, eight primary level schools, and two which were in rural areas. Geographic distribution was non-random. Participants had received medical clearance at the beginning of the school year, which was requested by schools for participation in physical education activities. Subjects with a clinical diagnosis of diabetes, asthma, musculoskeletal conditions or any other health problem limiting or preventing physical activity were excluded. A written informed consent was obtained from parents and students following a detailed explanation of study objectives. This research was approved by the Bioethics Committee of Universidad Adventista del Plata.

\section{Procedures}

Before starting the study, researchers and nine physical education teachers performed three theoretical-practical sessions so as to standardize the entire assessment process. ${ }^{14,15}$ In addition, teachers administered the ALPHA test battery once at the different schools in order to become familiar with the tests.

\section{Physical fitness assessment}

The high priority version of the ALPHA test battery was applied, leaving out the handgrip strength test using a dynamometer, but including the speed/agility $4 \times 10 \mathrm{~m}$ shuttle run test, proposed in the extended version. ${ }^{13,15}$ The assessment was performed in the following order: 1) Morphological component: Weight, height and waist circumference were measured as per the established protocols. ${ }^{14,15}$ Participants were weighed barefoot using a portable electronic scale OMROM HBF-500INT, with a 0.100 $\mathrm{kg}$ accuracy. Height was measured using a stadiometer (SECA 206). Participants were classified as overweight or obese as per Cole's criteria. ${ }^{16}$ Waist circumference was measured using an anthropometric unstretchable tape (W606PM, Lufkin, US).

2) Musculoskeletal component: The standing long jump (SLJ) test was used as an indicator of lower limb strength. It consists of jumping the longest distance possible from a standing start (without racing ahead) and swinging both arms. The distance is measured from the take off line to the point where the back of the heel nearest to the take off line lands on the ground.

3) Motor component: The speed/agility $4 \times 10 \mathrm{~m}$ shuttle run test was used as a comprehensive indicator of speed of movement, agility and coordination. ${ }^{14}$ It consists of running back and forth between two lines $10 \mathrm{~m}$ apart taking three sponges alternately as quickly as possible. The total distance run is $40 \mathrm{~m}$.

4) Cardiorespiratory component: This component was evaluated with the coursenavette test $(\mathrm{CN}-20 \mathrm{~m})$. It consists of running back and forth in both directions on a $20 \mathrm{~m}$ track marked between two separate lines. The rhythm is set by means of audio signals. The initial speed is $8.5 \mathrm{~km} / \mathrm{h}^{-1}$ and is increased by $0.5 \mathrm{~km} / \mathrm{h}^{-1}$ intervals every 1 minute, each called a stage. Subjects should step behind the $20 \mathrm{~m}$ line at the exact time that the audio signal or beep is heard. The test finishes when the subject stops because of fatigue or fails to reach the end line concurrent with the audio signal or beep on two consecutive occasions. Aerobic performance is expressed by the number of laps, i.e. the number of times a participant completes the $20 \mathrm{~m}$ track (1 lap $=20 \mathrm{~m}$ ). Additionally, the complete stage as well as one stage and a half were recorded. For example, if a subject completed stage 4 and reached half of the following stage, it is indicated as 4.5 (when considering a stage and a half), while it is indicated as 4 when analyzing only the last completed stage.

Aerobic capacity was determined using the maximal oxygen consumption ( $\mathrm{VO}_{2}$ max.), estimated as per Léger equation: ${ }^{17} \mathrm{VO}_{2}$ 
$\max =31.025+3.238 * \mathrm{~V}-3.248 * \mathrm{~A}+0.1536 * \mathrm{~V}$ ${ }^{*} \mathrm{~A}$. Here, $\mathrm{V}$ accounts for velocity (in $\mathrm{km} / \mathrm{h}^{-1}$ ) of the last completed stage and A accounts for the subject's age (in years). Participants were classified as having a healthy aerobic capacity if $\mathrm{VO}_{2}$ max. was $42 \mathrm{~mL} / \mathrm{kg} / \mathrm{min}$ for boys and $35-40 \mathrm{~mL} / \mathrm{kg} / \mathrm{min}^{-1}$ for girls, according to their age. Participants with lower values were classified as having an unhealthy aerobic capacity or as indicative of future cardiovascular risk, as established in the Fitnessgram ${ }^{\circledR}$ test. $^{2,7}$

Each test was performed twice, except for the CN-20 m, which was conducted only once. For data analysis, the average value was used in the case of the morphological component, while the best performance value was used for the other tests.

\section{Statistical analysis}

Data were analyzed using the SPSS software, version 18.0, and expressed using average values and standard deviation (SD), unless otherwise indicated. The normality of variables was determined using the Kolmogorov-Smirnov test. The Mann-Whitney U, non parametric test was used to analyze differences between sexes, by age groups (6 to 12 year old children and 13 to 19 year old adolescents) and the aerobic capacity level (health vs. unhealthy). This was performed before confirming the lack of normality in some of the outcome measures of the study. The accepted level of significance was $p<0.05$. To present percentile tables and curves for the main PF tests, smoothed percentile curves were determined by using the LMS procedure. ${ }^{18}$ This analysis was performed with the LMS Chart Maker Light software, version 2.54. Given the low number of 6 to 10 year old and 18 to 19 year old participants, it was not possible to estimate percentile values for these age groups, here percentiles for 11 to 17 year old, male and female children and adolescents are presented.

\section{RESULTS}

A total of 1867 children and adolescents (967 girls) were assessed. During the study, none of the participants had discomfort, pain or muscle-joint injuries. Table 1 shows the sample characteristics and the values obtained in the PF tests for children and adolescents. In both groups, male participants showed a better performance in PF tests. The proportion of subjects with an aerobic capacity indicative of future cardiovascular risk was $31.6 \%$. An unhealthy aerobic capacity was observed in $11.5 \%$ of children and $49.1 \%$ of adolescents $(<0.001)$. Only the children group showed significant differences between male and female participants regarding the prevalence of an unhealthy aerobic capacity $(p<0.001)$.

Tables 2-4 show PF values in an Argentine youth sample, classified by age and sex, and expressed using the $5^{\text {th }}, 25^{\text {th }}, 50^{\text {th }}, 75^{\text {th }}$ and $95^{\text {th }}$ percentiles. The $5^{\text {th }}$ percentile (P5) for the stage and a half completion in the $\mathrm{CN}-20 \mathrm{~m}$ test ranged between 1.5-3.6 and between 1.3-1.6 for males and females, respectively (Table 4). Percentile curves depict a clear trend between increasing PF levels and increasing age among male participants (Figure 1). On the contrary, as far as female participants, curves show stability or a mild increase in PF levels with increasing age (Figure 1).

Table 5 shows that children with a healthy aerobic capacity have higher levels of lower limb strength (only females), and lower body mass index (BMI) and waist circumference (both males and females). In addition, the prevalence of overweight and obesity was lower in the group with a healthy aerobic capacity: $22.2 \%$ vs. $75.8 \%$ for male participants $(p=0.001)$ and $32.2 \%$ vs. $57.9 \%$ for female participants $(p=0.027)$. In turn, adolescents with a healthy aerobic capacity had a superior lower limb strength, higher speed/ agility, a lower BMI, a lower waist circumference (females only) and a lower overweight and obesity prevalence: $19 \%$ vs. $39.3 \%$ for male participants ( $p=0.001)$ and $12.1 \%$ vs. $27.8 \%$ for female participants $(p=0.001)$.

\section{DISCUSSION}

This is the first published research study using the ALPHA test battery in a sample of 1867 Argentine children and adolescents. The ALPHA test battery was administered in ten cities from five provinces from across all cardinal points of Argentine (north, south, east and west). Up to this date, there has been no other similar published study in an Argentine pediatric population.

Tables 2-4 show the first percentiles of the ALPHA test battery (in the Argentine population) in order to interpret or score PF levels and allow comparisons with future studies. Different PF cutoff points were observed in the bibliography. On the one side, Ortega, et al. refer to the P5 levels of PF as "pathological PF level"19 or as a "warning sign," 20 so that youth in or below the $P_{5}$ should be examined to determine whether they have a cardiovascular risk factor. On the other side, Silva indicated that, in the case of the number of stages completed in the 


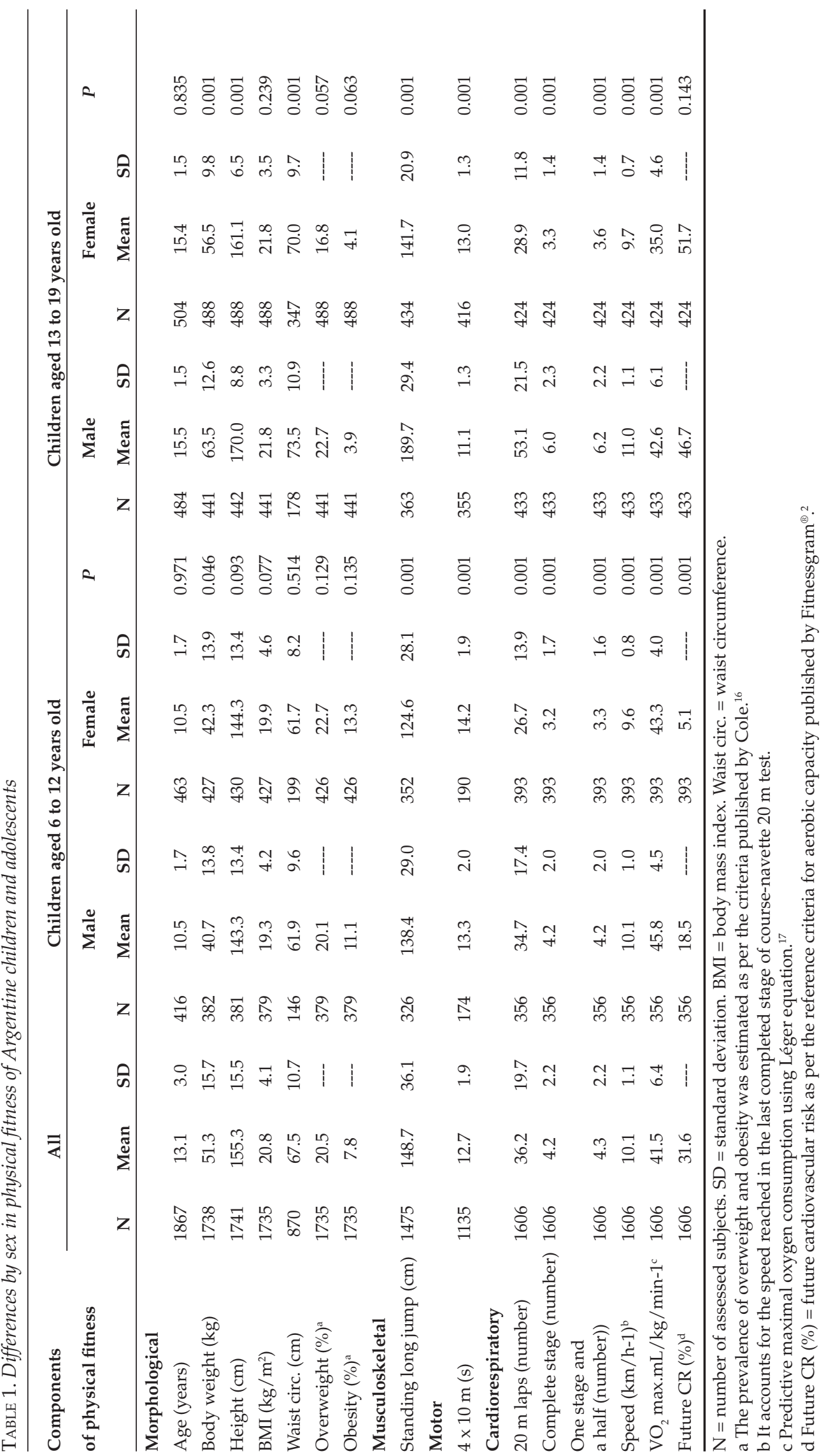


TABLE 2. Percentile values for lower limb strength test: standing long jump (cm)

\begin{tabular}{lccccccccccc}
\hline & $\mathbf{N}$ & Mean & $\mathbf{S D}$ & $\mathbf{L}$ & $\mathbf{M}$ & $\mathbf{S}$ & $\mathbf{P}_{5}$ & $\mathbf{P}_{25}$ & $\mathbf{P}_{50}$ & $\mathbf{P}_{75}$ & $\mathbf{P}_{95}$ \\
\hline Female & & & & & & & & & & & \\
11 years old & 124 & 133.2 & 27.5 & 1.617 & 135.6 & 0.188 & 88.2 & 117.6 & 135.6 & 152.2 & 174.2 \\
12 years old & 105 & 134.8 & 20.9 & 1.598 & 134.5 & 0.167 & 93.7 & 118.8 & 134.5 & 149.2 & 169.0 \\
13 years old & 95 & 134.8 & 18.6 & 1.493 & 135.8 & 0.153 & 99.1 & 121.4 & 135.8 & 149.5 & 168.2 \\
14 years old & 92 & 140.7 & 22.8 & 1.296 & 138.8 & 0.147 & 103.9 & 124.8 & 138.8 & 152.3 & 171.2 \\
15 years old & 62 & 143.8 & 20.2 & 0.984 & 142.1 & 0.146 & 108.2 & 128.2 & 142.1 & 156.1 & 176.2 \\
16 years old & 96 & 147.1 & 21.7 & 0.523 & 144.7 & 0.149 & 111.2 & 130.5 & 144.7 & 159.6 & 182.2 \\
17 years old & 68 & 140.8 & 21.9 & -0.056 & 143.6 & 0.156 & 111.2 & 129.2 & 143.6 & 159.6 & 186.0 \\
Male & & & & & & & & & & & \\
11 years old & 84 & 139.3 & 26.7 & 1.593 & 138.1 & 0.185 & 91.2 & 120.2 & 138.1 & 154.8 & 177.0 \\
12 years old & 108 & 152.8 & 26.6 & 1.400 & 150.3 & 0.167 & 106.2 & 132.9 & 150.3 & 166.8 & 189.6 \\
13 years old & 68 & 161.5 & 25.6 & 1.250 & 161.7 & 0.150 & 120.2 & 145.0 & 161.7 & 177.9 & 200.6 \\
14 years old & 62 & 179.0 & 23.5 & 1.246 & 174.3 & 0.136 & 134.2 & 158.2 & 174.3 & 190.1 & 212.3 \\
15 years old & 92 & 194.9 & 23.0 & 1.516 & 189.2 & 0.124 & 148.2 & 173.0 & 189.2 & 204.7 & 225.9 \\
16 years old & 90 & 202.7 & 25.0 & 2.017 & 200.6 & 0.116 & 157.7 & 184.2 & 200.6 & 215.7 & 235.7 \\
17 years old & 36 & 206.0 & 29.4 & 2.608 & 208.0 & 0.111 & 162.2 & 191.3 & 208.0 & 222.8 & 241.6 \\
\hline
\end{tabular}

Smoothing of percentiles was done by using the LMS procedure. $18 \mathrm{~N}=$ number of assessed subjects. The total sample was made up of 1182 subjects. $\mathrm{SD}=$ standard deviation; $\mathrm{L}=$ asymmetry; $\mathrm{M}=$ median; $\mathrm{S}=$ variation coefficient.

TABLE 3. Percentile values for the speed/agility test: $4 x 10 \mathrm{~m}$ (s)

\begin{tabular}{lccccccccccc}
\hline & $\mathbf{N}$ & Mean & $\mathbf{S D}$ & $\mathbf{L}$ & $\mathbf{M}$ & $\mathbf{S}$ & $\mathbf{P}_{5}$ & $\mathbf{P}_{25}$ & $\mathbf{P}_{50}$ & $\mathbf{P}_{75}$ & $\mathbf{P}_{95}$ \\
\hline Female & & & & & & & & & & \\
11 years old & 51 & 13.3 & 1.8 & -3.612 & 12.8 & 0.105 & 16.8 & 13.9 & 12.8 & 12.0 & 11.2 \\
12 years old & 51 & 13.3 & 1.5 & -2.990 & 13.0 & 0.103 & 16.5 & 14.1 & 13.0 & 12.2 & 11.4 \\
13 years old & 85 & 13.2 & 1.3 & -2.326 & 13.1 & 0.100 & 16.1 & 14.1 & 13.1 & 12.3 & 11.4 \\
14 years old & 86 & 13.1 & 1.5 & -1.705 & 13.0 & 0.097 & 15.7 & 13.9 & 13.0 & 12.2 & 11.3 \\
15 years old & 61 & 13.1 & 1.2 & -1.221 & 12.9 & 0.094 & 15.3 & 13.8 & 12.9 & 12.1 & 11.2 \\
16 years old & 96 & 12.8 & 1.1 & -0.790 & 12.8 & 0.092 & 15.0 & 13.6 & 12.8 & 12.0 & 11.1 \\
17 years old & 67 & 12.9 & 1.2 & -0.414 & 12.7 & 0.093 & 14.9 & 13.6 & 12.7 & 12.0 & 11.0 \\
Male & & & & & & & & & & & \\
11 years old & 29 & 12.2 & 1.8 & -1.530 & 12.2 & 0.142 & 16.3 & 13.6 & 12.2 & 11.2 & 10.0 \\
12 years old & 51 & 12.4 & 2.1 & -1.444 & 12.0 & 0.133 & 15.6 & 13.2 & 12.0 & 11.0 & 9.9 \\
13 years old & 48 & 11.6 & 1.1 & -1.418 & 11.7 & 0.123 & 14.8 & 12.7 & 11.7 & 10.8 & 9.7 \\
14 years old & 62 & 11.6 & 1.5 & -1.616 & 11.4 & 0.114 & 14.3 & 12.4 & 11.4 & 10.6 & 9.7 \\
15 years old & 91 & 11.2 & 1.3 & -2.022 & 11.1 & 0.106 & 13.7 & 12.0 & 11.1 & 10.4 & 9.6 \\
16 years old & 96 & 10.7 & 1.1 & -2.469 & 10.7 & 0.097 & 13.1 & 11.5 & 10.7 & 10.1 & 9.4 \\
17 years old & 41 & 10.9 & 1.1 & -2.838 & 10.6 & 0.090 & 12.9 & 11.4 & 10.6 & 10.1 & 9.4 \\
\hline
\end{tabular}

Smoothing of percentiles was done by using the LMS procedure.18 $\mathrm{N}=$ number of assessed subjects. The total sample was made up of 915 subjects. $\mathrm{SD}=$ standard deviation; $\mathrm{L}=$ asymmetry; $\mathrm{M}=$ median; $\mathrm{S}=$ variation coefficient.

TABLE 4. Percentile values for course-navette $20 \mathrm{~m}$ test (stage and a half)

\begin{tabular}{lccccccccccc}
\hline & $\mathbf{N}$ & Mean & $\mathbf{S D}$ & $\mathbf{L}$ & $\mathbf{M}$ & $\mathbf{S}$ & $\mathbf{P}_{\mathbf{5}}$ & $\mathbf{P}_{\mathbf{2 5}}$ & $\mathbf{P}_{\mathbf{5 0}}$ & $\mathbf{P}_{\mathbf{7 5}}$ & $\mathbf{P}_{\mathbf{9 5}}$ \\
\hline Female & & & & & & & & & & & \\
11 years old & 137 & 3.7 & 1.9 & 0.428 & 3.6 & 0.496 & 1.3 & 2.5 & 3.6 & 4.9 & 7.2 \\
12 years old & 106 & 3.8 & 1.4 & 0.429 & 3.5 & 0.457 & 1.4 & 2.5 & 3.5 & 4.6 & 6.7 \\
13 years old & 89 & 3.4 & 1.3 & 0.414 & 3.3 & 0.429 & 1.5 & 2.5 & 3.3 & 4.4 & 6.2 \\
14 years old & 95 & 3.4 & 1.5 & 0.384 & 3.2 & 0.417 & 1.4 & 2.4 & 3.2 & 4.1 & 5.8 \\
15 years old & 57 & 3.8 & 1.7 & 0.380 & 3.4 & 0.418 & 1.5 & 2.5 & 3.4 & 4.4 & 6.2 \\
16 years old & 95 & 3.6 & 1.5 & 0.413 & 3.5 & 0.417 & 1.6 & 2.6 & 3.5 & 4.6 & 6.5 \\
17 years old & 69 & 3.8 & 1.4 & 0.470 & 3.6 & 0.412 & 1.6 & 2.7 & 3.6 & 4.6 & 6.4 \\
Male & & & & & & & & & & & \\
11 years old & 90 & 4.6 & 1.8 & 0.953 & 4.7 & 0.419 & 1.5 & 3.4 & 4.7 & 6.0 & 8.0 \\
12 years old & 111 & 5.1 & 2.1 & 0.777 & 5.0 & 0.412 & 1.9 & 3.6 & 5.0 & 6.4 & 8.6 \\
13 years old & 78 & 5.1 & 2.1 & 0.628 & 4.9 & 0.399 & 2.1 & 3.6 & 4.9 & 6.2 & 8.4 \\
14 years old & 81 & 5.3 & 1.9 & 0.576 & 5.0 & 0.382 & 2.3 & 3.8 & 5.0 & 6.4 & 8.6 \\
15 years old & 110 & 6.3 & 2.1 & 0.635 & 5.8 & 0.360 & 2.7 & 4.4 & 5.8 & 7.2 & 9.5 \\
16 years old & 88 & 7.1 & 2.2 & 0.782 & 6.7 & 0.332 & 3.3 & 5.2 & 6.7 & 8.2 & 10.5 \\
17 years old & 53 & 6.5 & 2.1 & 0.975 & 7.0 & 0.300 & 3.6 & 5.6 & 7.0 & 8.4 & 10.4 \\
\hline
\end{tabular}

Smoothing of percentiles was done by using the LMS procedure. $18 \mathrm{~N}=$ number of assessed subjects. The total sample was made up of 1259 subjects. $\mathrm{SD}=$ standard deviation; $\mathrm{L}=$ asymmetry; $\mathrm{M}=$ median; $\mathrm{S}=$ variation coefficient. 
Figure 1. Percentile curves (from bottom to top: P5, P25, P50, P75, P95) of physical fitness in relation to health. Percentile curves were smoothed using the LMS procedure.18 CN-20 m=course-navette $20 m$ test

Physical fitness levels in Argentine children and adolescents.

Percentile curves $\left(\mathbf{P}_{5}, \mathbf{P}_{25}, \mathbf{P}_{50}, \mathbf{P}_{75}, \mathbf{P}_{95}\right)$

Males

Musculoskeletal component
Females

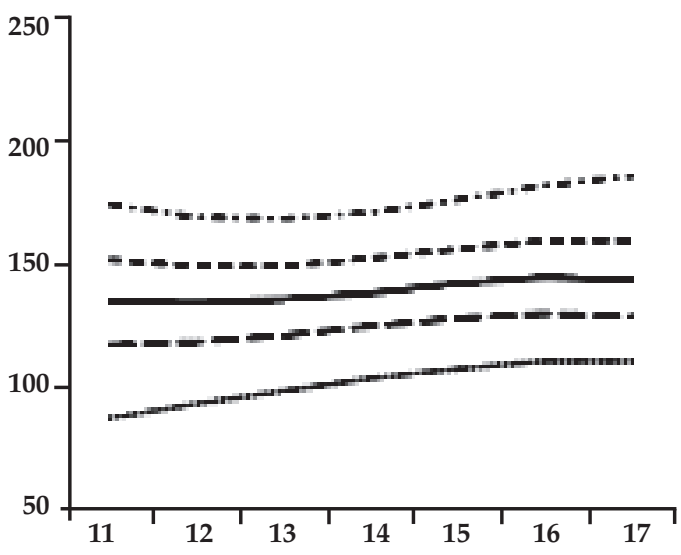

Age (years)

Motor component
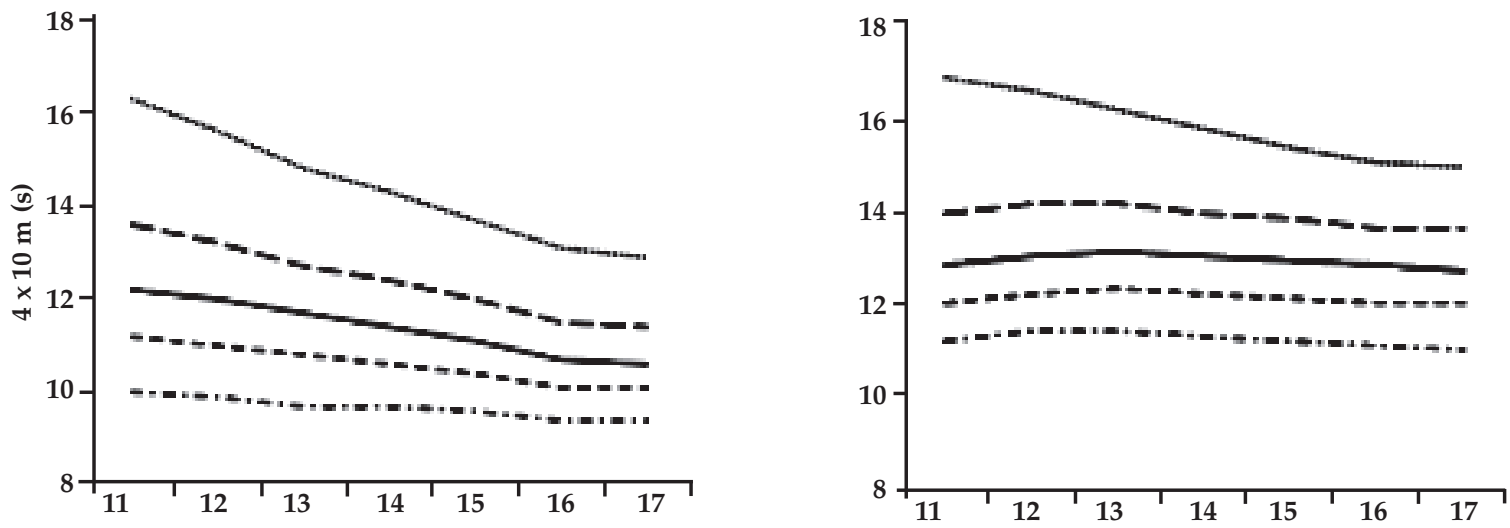

Age (years)

Cardiorespiratory component
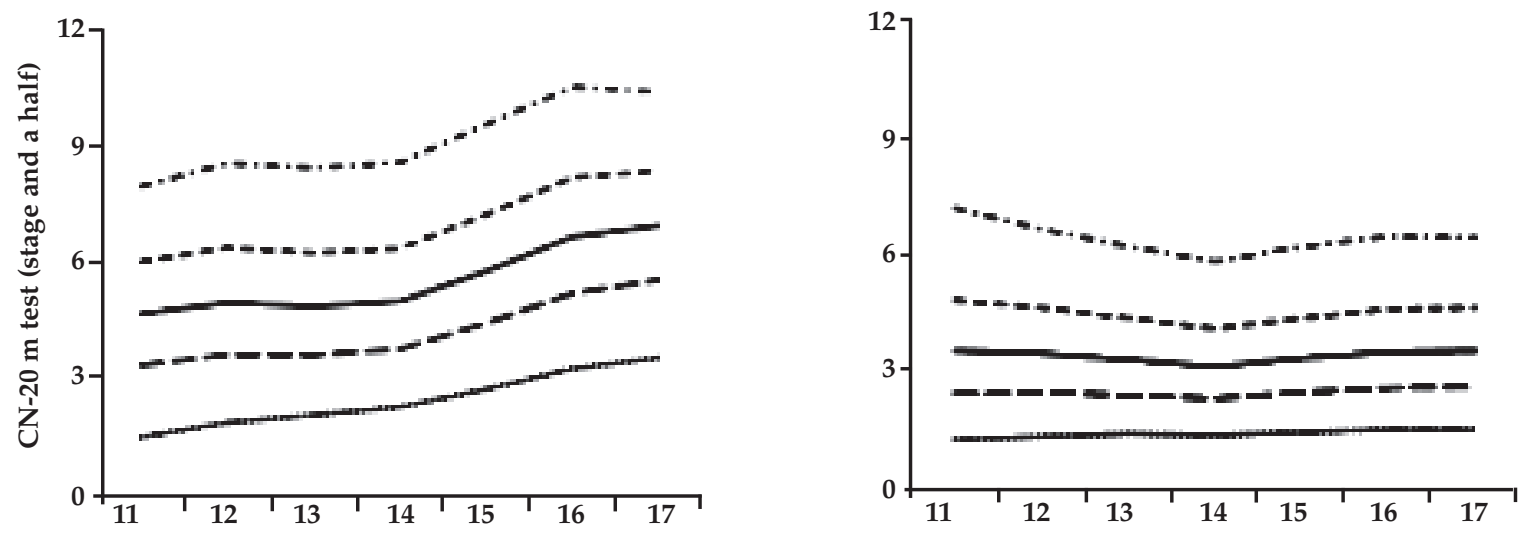

Age (years) 
$\mathrm{CN}-20 \mathrm{~m}$, the $40^{\text {th }}$ percentile was the most accurate cut-off point for the diagnosis of a high metabolic risk in Portuguese youth (aged 10 to 18 years old). ${ }^{6}$ Future studies should focus on the validation of cut-off points for tests that assess the different PF components in the Argentine population.

\section{Differences in PF levels among age and sex groups}

In line with prior studies, ${ }^{19-23}$ strength levels, speed/agility, performance, and aerobic capacity in this study were higher among male participants. The magnitude of such difference increased with age, and it was broader in the adolescent group $(12.7 \%$ to $46.2 \%)$ than in the children group ( $5 \%$ to $22.8 \%$ ). The reasons for a lower performance among children could be attributed to their lower muscle mass in relation to body weight and neuromuscular coordination. ${ }^{24}$

Other differences between sexes were observed in terms of speed reached in the CN$20 \mathrm{~m}$ test and the predictive $\mathrm{VO}_{2}$ max. Such differences are similar to those reported in other studies conducted on children and adolescents. ${ }^{17,25-29}$ Notwithstanding, greater differences in the predictive $\mathrm{VO}_{2}$ max. were observed in young adults when compared to our study's children and adolescents. ${ }^{4,30}$

\section{Levels of physical fitness compared to other countries}

A total of 19 studies (13 countries) compared PF levels by sex. Lower limb strength was assessed using the SL test in eight studies, ${ }^{11,19-23,31,32}$ speed/agility was assessed using the $4 \times 10 \mathrm{~m}$ in three studies, ${ }^{19,20,21}$ and aerobic performance was assessed using the CN-20 m test in 17 studies. ${ }^{5,6,11,17,19-21,23,25-29,31,33-35}$

Strength levels in male participants were higher compared to two studies, ${ }^{1,20}$ similar compared to five studies, ${ }^{19,21-23,31}$ and lower compared to one study. ${ }^{32}$ Strength levels in female participants were only mildly superior compared to two studies, ${ }^{11,32}$ similar compared to two studies, ${ }^{22,31}$ and lower compared to four studies. ${ }^{19-21,23}$ In terms of speed/agility, the values for males were similar to those of three studies, ${ }^{19-21}$ while females' performance was lower than that of the three analyzed studies. ${ }^{19-21}$

TABLE 5. Differences in the morphological. musculoskeletal and motor components between healthy aerobic capacity and unhealthy aerobic capacity groups in Argentine children and adolescents

\begin{tabular}{|c|c|c|c|c|c|c|}
\hline \multirow[t]{2}{*}{ PF component } & \multirow[t]{2}{*}{ Parameter } & \multirow[t]{2}{*}{ Age group } & \multirow[t]{2}{*}{ Gender } & \multicolumn{2}{|c|}{ Aerobic capacity } & \multirow[t]{2}{*}{$p$ value } \\
\hline & & & & Unhealthy & Healthy & \\
\hline \multirow[t]{12}{*}{ Morphological } & \multirow[t]{4}{*}{$\mathrm{BMI}^{\mathrm{b}}\left(\mathrm{kg} / \mathrm{m}^{2}\right)$} & \multirow[t]{2}{*}{ Children } & Male & $24.6 \pm 4.9$ & $18.3 \pm 3.2$ & 0.001 \\
\hline & & & Female & $24.1 \pm 5.1$ & $19.7 \pm 4.3$ & 0.001 \\
\hline & & \multirow[t]{2}{*}{ Adolescents } & Male & $23.0 \pm 3.8$ & $21.1 \pm 2.6$ & 0.001 \\
\hline & & & Female & $22.6 \pm 3.7$ & $20.6 \pm 2.4$ & 0.001 \\
\hline & \multirow[t]{4}{*}{ Waist circumference $(\mathrm{cm})$} & \multirow[t]{2}{*}{ Children } & Male & $80.3 \pm 11.6$ & $60.9 \pm 7.8$ & 0.001 \\
\hline & & & Female & $74.2 \pm 11.9$ & $62.1 \pm 7.8$ & 0.012 \\
\hline & & \multirow[t]{2}{*}{ Adolescents } & Male & $73.9 \pm 12.6$ & $73.5 \pm 11.1$ & 0.886 \\
\hline & & & Female & $71.7 \pm 10.6$ & $68.2 \pm 8.0$ & 0.003 \\
\hline & \multirow{4}{*}{ Overweight and obesity (\%) } & \multirow{2}{*}{ Children } & Male & $75.8(\%)$ & $22.2(\%)$ & 0.001 \\
\hline & & & Female & $57.9(\%)$ & $32.2(\%)$ & 0.027 \\
\hline & & \multirow[t]{2}{*}{ Adolescents } & Male & $39.3(\%)$ & $19.0(\%)$ & 0.001 \\
\hline & & & Female & $27.8(\%)$ & $12.1(\%)$ & 0.001 \\
\hline \multirow[t]{4}{*}{ Musculoskeletal } & \multirow[t]{4}{*}{1 Standing long jump $(\mathrm{cm})$} & \multirow[t]{2}{*}{ Children } & Male & $138.4 \pm 20.9$ & $145.6 \pm 21.3$ & 0.686 \\
\hline & & & Female & $109.5 \pm 26.7$ & $125.5 \pm 28.3$ & 0.020 \\
\hline & & \multirow[t]{2}{*}{ Adolescents } & Male & $179.9 \pm 29.1$ & $196.4 \pm 28.3$ & 0.001 \\
\hline & & & Female & $136.7 \pm 26.3$ & $137.9 \pm 31.5$ & 0.001 \\
\hline \multirow[t]{4}{*}{ Motor } & \multirow{4}{*}{$\begin{array}{l}\text { Speed/agility } \\
4 \times 10 \mathrm{~m} \text { test (s) }\end{array}$} & \multirow[t]{2}{*}{ Children } & Male & $12.9 \pm 1.9$ & $13.3 \pm 2.1$ & 0.331 \\
\hline & & & Female & $14.9 \pm 2.3$ & $13.8 \pm 1.7$ & 0.173 \\
\hline & & \multirow[t]{2}{*}{ Adolescents } & Male & $11.4 \pm 1.4$ & $11.0 \pm 1.2$ & 0.009 \\
\hline & & & Female & $13.3 \pm 1.4$ & $12.7 \pm 1.1$ & 0.001 \\
\hline
\end{tabular}

Participants were grouped by age: children (6 to 12 years old) and adolescents (13 to 19 years old). sex and aerobic capacity level (healthy and unhealthy) as per the Fitnessgram ${ }^{\circledR}$ reference criteria. ${ }^{2}$ Data were presented as average and standard deviation. except for overweight and obesity prevalence. a. $\mathrm{PF}=$ physical fitness. $\mathrm{b}$. $\mathrm{BMI}=$ body mass index. 
In relation to aerobic performance, male participants showed higher levels compared to one study,$^{34}$ similar or mildly lower compared to six studies, $, 111,23,27,31,35$ and lower compared to ten studies. ${ }^{6,17,19-21,25,26,28,29,33}$ In the case of female participants, values were similar in relation to six studies, $5,11,23,31,34,35$ and lower in relation to eleven studies. ${ }^{6,17,19-21,25-29,33}$ Comparing physical performance allows to establish that this sample of Argentine children and adolescents has one of the lowest PF levels of all countries.

\section{Aerobic capacity and future cardiovascular risk}

When analyzing the total sample of the present study approximately 1 every 3 Argentine youth has an aerobic capacity indicative of future cardiovascular risk (Table 1). However, the age group analysis showed that the proportion of adolescents with an unhealthy aerobic capacity was markedly superior $(49.1 \%)$ in relation to the group of children $(11.5 \%)$. These values were higher than those observed in Spanish adolescents $^{19}(19.3 \%$ ond $17.3 \%$ + $)$, in European adolescents $^{20}$ (38\% ${ }^{\lambda}$ and $43 \%$ ㅇ) , in Australian children and adolescents ${ }^{23}(29 \%$ ond $23 \%$ \% $)$, and in American adolescents ${ }^{7}(29 \%$ and $31 \%$ ㅇ).

These results should be considered with caution because certain factors, such as the $\mathrm{VO}_{2}$ max. cut-off point, the equation applied to estimate $\mathrm{VO}_{2}$ max. and the test used, which may affect classifications. ${ }^{4}$ In relation to this, Secchi and García ${ }^{4}$ demonstrated that the $\mathrm{VO}_{2}$ max. predictive equation and the Fitnessgram ${ }^{\circledR}$ reference criteria ${ }^{2,3}$ significantly modify the proportion of young adults with cardiometabolic risk. The data obtained in this study show that, in general, children and adolescents with a healthy aerobic capacity had a better PF (Table 5). In addition, they had a lower waist circumference and a lower overweight and obesity prevalence, all factors related to an improved cardiovascular profile. ${ }^{9,10}$ Such evidence demonstrates that Physical Education teachers play the role of health promoters for their students. Therefore, the school setting is exceptional to promote exercise habits and preserve cardiovascular health. ${ }^{8}$

One of the strengths of this study is that it assessed PF using the ALPHA test battery, with proven validity, reliability, applicability and relation to health in children and adolescents. ${ }^{11-13}$ Among the study limitations it is worth mentioning that the sample is not representative and that the number of participants is relatively low to establish reference values for the Argentine pediatric population. However, given the lack of normative data regarding PF in this population, this study provides the first PF values using the ALPHA test battery in a population of Argentine students.

\section{CONCLUSIONS}

Argentine male children and adolescents in the sample showed greater levels of physical fitness. Such differences increase with age. Approximately one every three participants had an aerobic capacity indicative of future cardiovascular risk

\section{Acknowledgments}

We would like to thank Jonatan Ruiz for his contributions to enrich the study. To the Physical Education teachers who helped with the field work: Silvia Ruggiero, Alberto Espada, Tania Domato, Alexis Buchammer, Silvia Rode, Favio Rodríguez, Ramón Schwemmer, Andrea Rodríguez, and José Luis Sosa.

\section{REFERENCES}

1. Morrow JR Jr, Zhu W, Franks BD, Meredith MD, et al.19582008: 50 years of youth fitness tests in the United States. Res Q Exerc Sport 2009;80(1):1-11.

2. The Cooper Institute for Aerobics Research. FITNESSGRAM Test Administration Manual. 3rd ed. Champaign: Human Kinetics; 2004.Págs.38-9.

3. Welk GJ, Laurson KR, Eisenmann JC, Cureton KJ. Development of youth aerobic-capacity standards using receiver operating characteristic curves. Am J Prev Med 2011;41(4 Suppl 2):S111-6.

4. Secchi JD, García GC. Cardiorespiratory fitness and cardiometabolic risk in young adults. Rev Esp Salud Pública 2013;87:35-48.

5. Moreira C, Santos R, Ruiz JR, Vale S, et al. Comparison of different $\mathrm{VO} 2$ max equations in the ability to discriminate the metabolic risk in Portuguese adolescents. J Sci Med Sport 2011;14(1):79-84.

6. Silva G, Aires L, Mota J, Oliveira J, et al. Normative and criterion-related standards for shuttle run performance in youth. Pediatr Exerc Sci 2012;24(2):157-69.

7. Lobelo F, Pate RR, Dowda M, Liese AD, et al. Validity of cardiorespiratory fitness criterion-referenced standards for adolescents. Med Sci Sports Exerc 2009;41(6):1222-9.

8. Ardoy DN, Fernández-Rodríguez JM, Ruiz JR, Chillón P, et al. Improving physical fitness in adolescents through a school-based intervention: the EDUFIT study. Rev Esp Cardiol 2011;64(6):484-91.

9. Ortega FB, Ruiz JR, Castillo MJ, Sjostrom M. Physical fitness in childhood and adolescence: a powerful marker of health. Int J Obes (Lond) 2008;32(1):1-11.

10. Ruiz JR, Castro-Piñero J, Artero EG, Ortega FB, et al. Predictive validity of health-related fitness in youth: a systematic review. Br J Sports Med 2009;43(12):909-23.

11. España-Romero V, Artero EG, Jiménez-Pavón D, CuencaGarcía M, et al. Assessing health-related fitness tests in the school setting: reliability, feasibility and safety; the ALPHA Study. Int I Sports Med 2010;31(7):490-7.

12. Castro-Piñero J, Artero EG, España-Romero V, Ortega FB, 
et al. Criterion-related validity of field-based fitness tests in youth: a systematic review. Br J Sports Med 2010;44(13): 934- 43.

13. Ruiz JR, Castro-Piñero J, España-Romero V, Artero EG, et al. Field-based fitness assessment in young people: the ALPHA health-related fitness test battery for children and adolescents. Br J Sports Med 2011;45(6):518-24.

14. Ruiz JR. Health-related fitness assessment in childhood and adolescence: a European approach based on the AVENA, EYHS and HELENA studies. J Public Health 2006;14: 269- 77.

15. Manual de Instrucciones de la Batería ALPHA-Fitness: Test de campo para la evaluación de la condición física relacionada con la salud en niños y adolescentes. Accessed on: December 12, 2013]. Available at: https://sites.google.com/site/ alphaprojectphysicalactivity/alpha-public-documents/alphafit/assessing-fitness-in-children.

16. Cole TJ, Bellizzi MC, Flegal KM, Dietz WH. Establishing a standard definition forchild overweightand obesityworldwide: international survey. BMJ 2000;320:1240-3.

17. Léger LA,MercierD, GadouryC, LambertJ. Themultistage 20 metre shuttle run test for aerobic fitness. J Sports Sci 1988;6:93101.

18. Cole TJ, Green PJ. Smoothing reference centile curves: the LMS method and penalized likelihood. Stat Med 1992;11(10):1305-19.

19. Ortega FB, Ruiz JR, Castillo MJ, Moreno LA, et al. Low level of physical fitness in Spanish adolescents. Relevance for future cardiovascular health (AVENA study). Rev Esp Cardiol 2005;58(8):898-909.

20. Ortega FB, Artero EG, Ruiz JR, España-Romero V, et al. Physical fitness levels among European adolescents: the HELENA study. Br J Sports Med 2011;45(1):20-9.

21. Ortega FB, Artero EG, Ruiz JR, Vicente-Rodríguez G, et al. Reliability of health-related physical fitness tests in European adolescents. The HELENA Study. Int J Obes (Lond) 2008;32(Suppl 5):S49-57.

22. Castro-Piñero J, González-Montesinos JL, Mora J, Keating $\mathrm{XD}$, et al. Percentile values for muscular strength field tests in children aged 6 to 17 years: influence of weight status. J Strength Cond Res 2009;23(8):2295-310.

23. Catley MJ, Tomkinson GR. Normative health-related fitness values for children: analysis of 85347 test results on 9-17-year-old Australians since 1985. Br J Sports Med 2013;47(2):98-108.

24. Bar-Or O, Rowland TW. Pediatric Exercise Medicine: from physiologic principles to health care application. United States: Human Kinetics; 2004. Págs.3-19.

25. Léger L, Lambert A, Goulet A, Rowan C, et al. Capacity aerobic des Quebecons de 6a 17 ans: test navette de 20 metres avec paliers de 1 minute. Can J Appl Sport Sci 1984;9:64-9.

26. Matsuzaka A, Takahashi Y, Yamazoe M, Kumakura N, et al. Validity of the Multistage 20-MShuttle-Run Test for Japanese Children,Adolescents, and Adults. Pediatr ExercSci2004;16:11325.

27. Beets MW, Pitetti KH. A comparison of shuttle-run performance between midwestern youth and their national and international counterparts. Pediatr Exerc Sci 2004;16:94112.

28. Liu NYS, Plowman SA, Looney MA. The reliability and validity of the 20-meter shuttle test in American students 12 to 15 years old. Res Q Exerc Sport 1992;63:360-5.

29. Barnett A, Chan LY, Bruce IC. A preliminary study of the 20-m multistage shuttle run test as a predictor of peak VO2 in Hong Kong Chinese students. Pediatr Exerc Sci 1993;5:4250.

30. García GC, SecchiJD. Relationship between the final speeds reached in the 20 metre Course Navette and the MAS-EVAL test. A proposal to predict the maximal aerobic speed. Apunts Med Esport 2013;48(177):27-34.

31. Baquet G, Twisk JW, Kemper HC, Van Praagh E, Berthoin S. Longitudinal Follow-up of fitness during childhood: interaction with physical activity. Am J Hum Biol 2006;18(1):51-8.

32. Artero EG, España-Romero V, Castro-Piñero J, Ruiz J, et al. Criterion-related validity of field-based muscular fitness tests in youth. J Sports Med Phys Fitness 2012;52(3):263-72.

33. SlingerJ, Breda E, Kupiers H. Aerobic fitness data for Dutch adolescents (2002-2005). Pediatr Exerc Sci 2009;21:10-18.

34. Carrel AL, Bowser J, White D, Moberg DP, et al. Standardized childhood fitness percentiles derived from scholl-based testing. J Pediatr 2012;161(1):120-4.

35. Sandercock G, Voss C, Cohen D, Taylor M, Stasinopoulos DM. Centile curves and normative values for the twenty metre shuttle-run test in English schoolchildren. J Sports Sci 2012;30(7):679-87. 